\title{
Synthesis and Characterization of Degradable Polycationic Polymers as Gene Delivery Carriers
}

\author{
Hyun Jin Kim, Min Sung Kwon, Joon Sig Choi," Bo Hye Kim, Jae Keun Yoon, Kwan Kim, and Jong-sang Park \\ School of Chemistry \& Molecthar Engineering. Seoul National Lniversitv, Seoul 151-742, Korea \\ ${ }^{\star}$ E-mail: pfospartaplazasnuac.kr \\ ${ }^{\dagger}$ Department of Biochemistry; Chungham National Universitw, Daejeon 305-764, Korea \\ Received November 1, 2006
}

\begin{abstract}
Biodegradable cationic poly(ester-amide) polymers were synthesized by double-monomer method. that showed excellent solubility in many organic solvents and water. Different degradation patterns were obtained by the regulation of monomer ratios and overall long period of time of DNA protection up to 12 days was shown by PicoGreen reagent assay. Good transfection profiles in the presence of senum and very low toxicity on mammalian cells may allow these polymers to become suitable for long-term gene delivery systems and therapeutic applications.
\end{abstract}

Key Words : Gene therapy. Gene delivery, Biodegradable poly mer

\section{Introduction}

The challenging researches in polymeric vectors for gene therapy have been developed to improve the treatment of several diseases for many years. One of the effective transfection vector systems is either viral vectors or vinus-associated sequences that display very efficient target cell-specific trasfection results. ${ }^{.}$However. immunogenic problems and unexpected stimulation of protooncogenes caused by using viral vectors have been seriously issued so far ${ }^{23}$ Among non-viral vectors. polycationic polymers are intensively studied for the self-assembling ability with DNA the formation of biocompatible nano-size particles. and the enhanced transport of DNA into the cell through the membrane. ${ }^{+}$The polyplex particles formed by cationic polymers have been characterized by charge density. size morphology. degradation and transfection efficiency. The non-degradable polymers with high charge densities and high molecular weight like PEI showed significant cellular toxicities which revealed the need for low-toxic. and degradable polymers possessing effective gene transfection efficacy. Many degradable polymers have been reported but most of them degrade relatively too fast to attain long-circulating or effective controlled release of the complexed therapeutic genes. ${ }^{5-9}$

\section{Materials and Methods}

Materials. Ethy lene diamine. Fmoc- $\varepsilon-\mathrm{Ah} x-\mathrm{OH}$. ethidium bromide. methyl acrylate. tris(2-hydroxyethyl)amine. MTT (3-[4.5-dimethylthiazol-2-yl]-2.5-diphenyltetrazolium bromide). N.N-Diisopropyllethylamine (DIPEA), piperidine (Hexahydropyridine), ethanolamine. PEI (average molecular weight $25 \mathrm{kDa}$ ), and trizma base (2-Amino-2-(hydroxymethyl)-1.3-propanediol). diethyl ether were purchased from Sigma-Aldrich (St. Louis. MO). Fmoc-6-aminohexanoic acid (Fmoc-eAhx) was purchased from Novabiochem (Laufelfin- gen. Switzerland). N.N.N'N'-tetramethỵl-O-(1H-benzotriazole-1-yl)uranium hexafluorephosphate (HBTU), and 1hydroxybenzotriazole ( $\mathrm{HOBt}$ ) were purchased from Anaspec. Inc. (San Jose. CA). Reporter Lysis Buffer. Luciferase 1000 Assay system was a product of Promega (Madison. WI). Dulbecco's modified Eagle's medium (DMEM) and fetal bovine senum (FBS) were purchased from GIBCO (Gaithersburg. MD). Micro BCA protein assay kit was purchased from PIERCE (Rockford. Il). PicoGreen was purchased from Molecular Probes (Eugene. OR).

Synthesis of monomer A4. Ethylenediamine methanol solution $(20 \mathrm{mmol}$ ) was added drop wise to a stirred solution of methyl acrylate $(1.5 \mathrm{~mol})$ at room temperature for $48 \mathrm{~h}$. Excess methyl acrylate including methanol were evaporated and final monomer A4 was obtained (99\%). ${ }^{1} \mathrm{H}$ NMR (300 $\mathrm{MHz}, \mathrm{DMSO}-\mathrm{d} 6$ ) $\delta 2.37$ (t. $4 \mathrm{H},-\mathrm{CH}_{2} \mathrm{CH}_{2} \mathrm{COO}$ ), 2.38 (s. $4 \mathrm{H}$. $-\mathrm{CH}_{2} \mathrm{~N}-$ ). 2.65 (t. $4 \mathrm{H}$. $-\mathrm{CH}_{2} \mathrm{CH}_{2} \mathrm{COO}$ ), 3.56 (s. $12 \mathrm{H}$. $-\left(H_{3}\right)$.

Synthesis of $A 4 B 4$ polymers and polymer surface modification. Four polymers were separately sy'nthesized by double monomer method as placing A4 monomer with increasing molar ratios of $\mathrm{B} 4$ (trizma base) monomer from 1.0 to 2.5 as Figure 1 in a glass vial at a temperature of 180 ${ }^{\circ} \mathrm{C}$ in a silicon bath. After $24 \mathrm{~h}$. the polymers were gained and kept in a dry condition at $-60^{\circ} \mathrm{C}$ deep freezer. Surface hydroxyl group was reacted with Fmoc- $\varepsilon$-Ahx-OH to introduce primary amine. All four polymers $(50 \mathrm{mg})$. Fmocc-Ahx-OH $(0.25 \mathrm{~g} .0 .70 \mathrm{mmol})$. l-hydroxybenzotriazole (HOBt. 0.95 g. $0.70 \mathrm{mmol}$ ). N.N.N'.N'-tetramethyl-O-(1Hbenzotriazole-1-yl)uranium hexafluorephosphate (HBTU. $0.27 \mathrm{~g} .0 .70 \mathrm{mmol}$ ), and N.N-Diisopropy lethylamine (DIPEA. $245 \mu \mathrm{L}, 1.41 \mathrm{nmmol}$ ) were dissolved in DMF at room temperature. After $12 \mathrm{~h}$. the solutions were three times precipitated in diethyl ether for purification. The Fmoc group was removed by vortexing the polymer in $15 \%$ piperidine in DMF ( $\mathrm{v} / \mathrm{v}$ ) solution for $5 \mathrm{~min}$. followed by purification in diethyl ether precipitation. leaving the final 


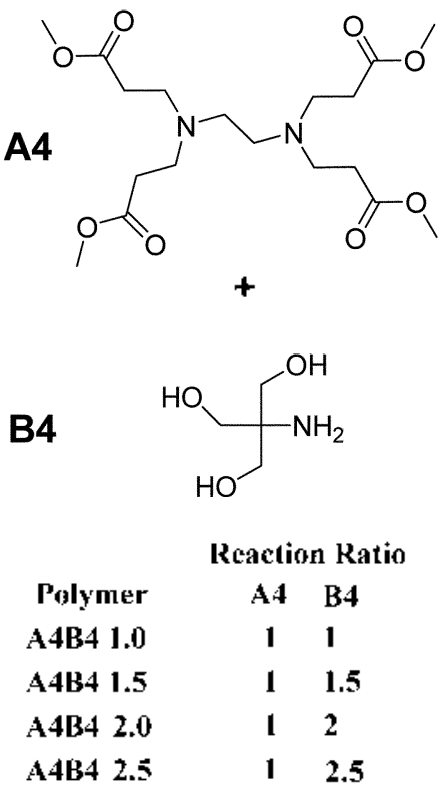

Figure 1. The monomer structures and their reaction ratios for the polymers.

products of $\mathrm{A} 4 \mathrm{~B} 4$ 1.0, $\mathrm{A} 4 \mathrm{~b} 4$ 1.5, $\mathrm{A} 4 \mathrm{~B} 4$ 2.0. and $\mathrm{A} 4 \mathrm{~B} 42.5$. NMR ( $300 \mathrm{MHz}, \mathrm{D} 2 \mathrm{O}) \delta 1.39$ (br, $\mathrm{NH}_{2} \mathrm{CH}_{2} \mathrm{CH}_{2} \mathrm{CH}_{2} \mathrm{CH}_{2} \mathrm{CH}_{2}$ ). 1.75 (br, $\mathrm{NH}_{2} \mathrm{CH}_{2} \mathrm{CH}_{2} \mathrm{CH}_{2} \mathrm{CH}_{2} \mathrm{CH}_{2}$ ). 2.41 (br. $\mathrm{NH}_{2} \mathrm{CH}_{2}-$ $\mathrm{CH}_{2} \mathrm{CH}_{2} \mathrm{CH}_{2} \mathrm{CH}_{2}$ ), 2.42 (br, $-\mathrm{CH}_{2} \mathrm{CH}_{2} \mathrm{COO}-$ ), 2.81 (br, $\mathrm{NH}_{2} \mathrm{CH}_{2} \mathrm{CH}_{2} \mathrm{CH}_{2} \mathrm{CH}_{2} \mathrm{CH}_{2}$ ), 2.48 (br, $-\mathrm{CH}_{2} \mathrm{~N}-$ ), 2.98 (t. $4 \mathrm{H}$, $-\mathrm{CH}_{2} \mathrm{CH}_{2} \mathrm{COO}$-), $4.1 \mathrm{l}$ (br, - $\mathrm{COOCH} \mathrm{H}_{i}$ ).

Primary amine quantification. Standard curve was obtained by ethanolamine solutions at increasing concentrations from 5 to $35 \mu \mathrm{g} / \mathrm{mL}$. Samples were put on a test

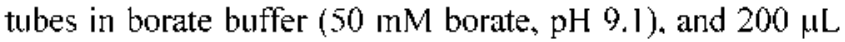
fluorescamine solution ( $\mathrm{l} \mathrm{mg/mL}$ fluorescamine in DMF) was added for $12 \mathrm{~min}$. Then $1.5 \mathrm{~mL}$ stop solution (DMF : water $=1:$ I) was added for measurement. The excitation and emission wavelengths were set to 390 and $475 \mathrm{~nm}$, respectively, by a SFM 25 spectrofluorometer (Jasco Instruments).

PicoGreen assay. Sample polymer in HBS buffer solutions (25 mM HEJ'ES, $150 \mathrm{mM} \mathrm{NaCl}, \mathrm{pH} 7.4$ ) was mixed with $1.0 \mu \mathrm{g} \mathrm{pCN}$ Luci and incubated at room temperature. After $30 \mathrm{~min}, 200 \mu \mathrm{L}$ working solution $(1 \mu \mathrm{L}$ of PicoGreen reagent diluted in $199 \mu \mathrm{L}$ l'E buffer $(10 \mathrm{mM}$ [ris, $1 \mathrm{mM}$ ED [A, pH 7.4)) was added for $2 \mathrm{~min}$ and diluted with 1600 $\mu \mathrm{L}$ TE buffer for measurement. SFM 25 spectrofluorometer (Jasco instruments) was used with the wavelength fixed at $480 \mathrm{~nm}$ for excitation $\left(\lambda_{\mathrm{cx}}\right)$ and $520 \mathrm{~nm}$ for emission $\left(\lambda_{\mathrm{ctII}}\right)$.

Multi Angle Laser Light Scattering (MALLS). Sizeexclusion chromatography was run on a chromatography system (Dionex) equipped of Waters Styragel HR3 and Styragel HR5E columns and DMF was used as a mobile phase at a flow rate of $0.5 \mathrm{~mL} / \mathrm{min}$. MALLS detector (mini DAWN DSP, Wyatt Technology, Santa Barbara, CA) was connected to SEC system. The refractive index increment ( $\mathrm{d} n / \mathrm{dc}$ ) was measured by Optilab DSP' (Wyatt Technology, Santa Barbara. CA).

Degradation studies. All polymers were dissolved in
PBS and separated into two groups; polyplex-solution group and polymer-solution group. both kept in a $37^{\circ} \mathrm{C}$ incubator. Polyplex-solution group was incubated after complex formation with DNA (polymer/DNA, at weight ratio 30), and polymer-solution group was incubated DNA free. Polymersolution group was inixed with $I \mu \mathrm{g} D N A$ for $30 \mathrm{~min}$ just before PicoGreen analysis until the polymer lost its selfcomplexing ability. PicoGreen measurement was used as above description.

Cell viability measurement. HepG2 (human hepatocellular carcinoma) cells were grown and seeded in 96-well plate at a density of 10000 cells per well in 10\% FBS (fetal bovine serum) containing MEM culture medium. Cells were grown for $24 \mathrm{~h}$ and indicated concentrations of polymer were added and left for $48 \mathrm{~h}$ exposure. Then the cells were washed and $26 \mu \mathrm{L}$ of $\mathrm{M}^{\prime} \mathrm{l} \mathrm{l}$ working solution $(2 \mathrm{mg} / \mathrm{mL}$ MI"I in l'BS, filtered through $0.2 \mu \mathrm{m}$ syringe filter) was added to each well. After $4 \mathrm{~h}$ incubation, the medium was removed and $150 \mu \mathrm{L}$ DMSO was added and mixed. Percentage intensity was measured by a microplate reader at $570 \mathrm{~nm}$ (Molecular Devices).

Atomic Force Microscopy (AFM). The AFM images of polyplex were obtained at the weight ratio of $1: 30$ (DNA : polymer) by $\mathrm{A} 4 \mathrm{~B} 42.0$ at terms of time. A4B4 2.0 polymer solution was kept at $37^{\circ} \mathrm{C}$ until measurement and $0.1 \mu \mathrm{g}$ of DNA was added to solutions then incubated for $30 \mathrm{~min}$ to form self-assembled particles. I $\mu \mathrm{L}$ of the polyplex solution was dropped on the middle of a clean mica surface and left for 1 min to adsorb. The remaining solution was removed and air dried. The images were obtained on tapping mode at a scanning speed of $5 \mathrm{~Hz}$ with a Nanoscope a instrument equipped with an E scanner (Digital Instruments, Santa Barbara, CA).

Transfection assay. HepGi2 were grown and seeded in a 24-well plate at a density of 50000 in MEM containing 10\% rBS at $37{ }^{\circ} \mathrm{C}$ incubator of $5 \% \mathrm{CO}_{2} 95 \%$ humidified air to reach $70 \%$ confluence. The polyplexes were added in $10 \%$ FBS containing condition and incubated for more $48 \mathrm{~h}$ then removed, washed with PBS, and followed by lysis. $120 \mu \mathrm{L}$ Reporter lysis buffer (Promega. Madison. WI) was added and centrifuged to obtain clear lysate. Luciferase activity was measured by automatic injection of $50 \mu \mathrm{L}$ Luciferase Assay Reagent (Promega, Madison, WI) for $10 \mathrm{~s}$ with a $2 \mathrm{~s}$ delay for $10 \mu \mathrm{L}$ lysate. Micro BCA reagent (Pierce. Rockford. IL) was used to determine protein concentration.

\section{Results and Discussion}

We designed an amide ester polymer containing random amide bonds in the ester backbone structure of the crosslinked polymer by multiple reactive moieties from two monomers, described as double-monomer methodology, Ax - By. ${ }^{10}$ The polycondensation of monomers $\mathrm{A} 4$ and $\mathrm{B} 4$ at four different ratios resulted in four types of polymers including biodegradable backbones constructed by ester and amide bonds (Figure 1). The four polymer derivatives were classified and named as A4B4 1.0, 1.5, 2.0 and 2.5, which 
means the mole ratio of Bt over At. Usually, in many cases. the polycondensation of monomers with multiple reactive functional moieties ended up with the fomation of gel-like polymers display ing poor solubility in various solvents. " but the four A4B4 polymers synthesized by double monomer method showed excellent solubility in water even in many organic solvents. The condensation of two monomers formed ester bonds in its polymer structure for biodegradation. and the degradability of the polymer backbone structure was designed to be regulated with primary amine in B4 monomer by increasing $\mathrm{B} 4$ amount. since the primary amine in B4 will form amide bonds instead of ester bonds. which affect to slower degradation profiles when more amide bonds were present in the structures.

Synthetic large cross-linked polymers have no reference substances and their mass was not obtained by gel permeation chromatography. So the size data was obtained by MALLS (multi-angle laser light scattering), combined with SEC without standards. in a well-established non-invasive method for estimating an absolute molar mass $\left(M_{w}\right)$ of polymer. Absolute mass $\left(\mathrm{M}_{w}\right)$ and polydispersity $\left(\mathrm{M}_{\mathrm{w}} / \mathrm{M}_{\mathrm{n}}\right)$ at the concentration of $20 \mathrm{mg} / \mathrm{mL}$ were calculated with Astra 4.81 .07 software (Wyatt Technology Corp.). As the B4 ratio increased. the molecular weight of the sy'nthesized polymer increased (Table 1). The surface primary amines were conjugated to the hydroxyl groups by coupling Fmoc- $\varepsilon$ Ahx-OH to the polymers. After Fmoc group deprotection. the quantity of the primary amines resulted 2.6. 3.0. 3.8. 3.6 $\mu \mathrm{mol} / \mathrm{mg}$ for A4B4 1.0. A4B4 1.5. A4B4 2.0. and A4B4 2.5. respectively:

The positively charged polymer self-assembled with DNA to form polymer/DNA polyplexes and the assembly degree was measured by PicoGreen reagent. PicoGreen is a very sensitive fluorescent dye which intercalates into double stranded DNA. ${ }^{12}$ Therefore, lower PicoGireen signals from polyplex indicate compact assembly and good DNA condensation. The polymers reached significantly low intensity at weight ratio 5 by all polymers. lower fluorescence at higher weight ratios. especially with A4B4 1.5.2.0. and 2.5. that have higher primary amine concentrations (Figure 2).

The morphology of DNA/polymer polyplex was observed by AFM. in terms of time (day) for its degradation images. as shown in Figure 3. The polymers condensed with DNA forming polyplexes had regular. globular shapes whereas polymer itself had random structures. Since the in vivo and in vitro conditions usually involve $\mathrm{DNA} /$ polymer polyplexes. the release of DNA from polyplex due to the degradation of

Table 1. Polvdispersity and averaged molecular weight ( $\mathrm{g} / \mathrm{mol}$ ) by MALLS at $690 \mathrm{~mm}$ laser wavelength collected at three angles, and extrapolated in a Zimun plot. *poly dispersity

\begin{tabular}{ccccc}
\hline & $\mathrm{M}_{1}$ & $\mathrm{M}_{w}$ & $\mathrm{M}_{2}$ & $\mathrm{M}_{\mathrm{w}} / \mathrm{M}_{\mathrm{n}}{ }^{*}$ \\
\hline A4B4 1.0 & $3.82 \times 10^{2}$ & $1.55 \times 10^{2}$ & $7.67 \times 10^{3}$ & 5.50 \\
A4B4 1.5 & $7.52 \times 10^{3}$ & $1.35 \times 10^{+}$ & $2.33 \times 10^{-1}$ & 1.77 \\
A4B4 2.0 & $157 \times 10^{3}$ & $3.74 \times 10^{2}$ & $2.17 \times 10^{5}$ & 2.37 \\
A4B4 2.5 & $2.56 \times 10^{3}$ & $1.11 \times 10^{-1}$ & $2.93 \times 10^{-4}$ & 4.69 \\
\hline
\end{tabular}

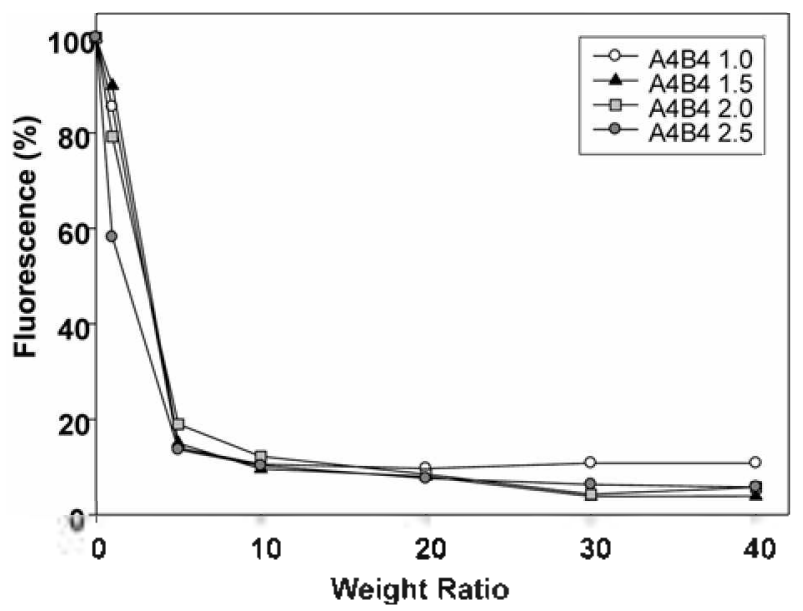

Figure 2. Polymer self-assembly assay by PicoGreen reagent.

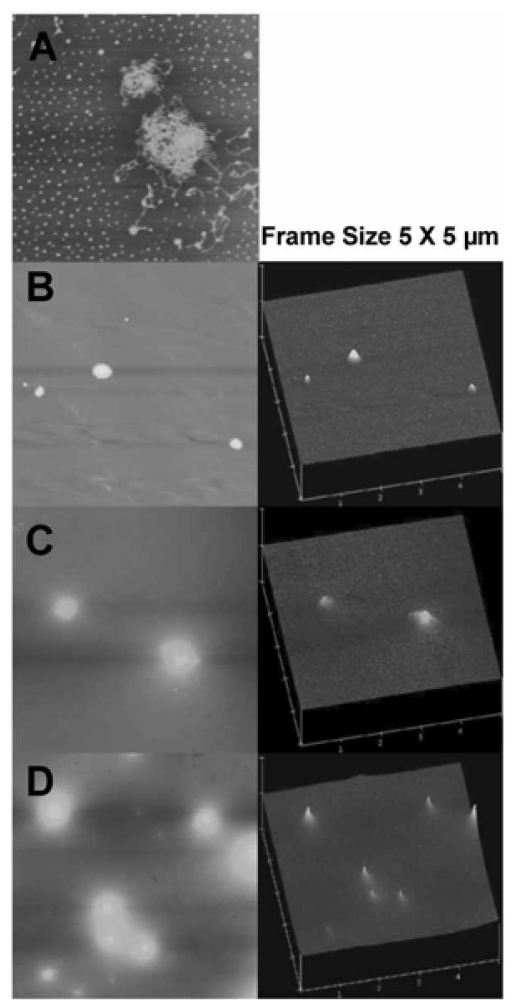

Figure 3. AFM images of A4B+ 2.0 at weight ratio $1: 30$ (DNA polymer) and its three-dimensional images. A) control DNA, B) at $0 \mathrm{~h}$, C) $24 \mathrm{~h}$, and D) $48 \mathrm{~h}$.

polymer is considered to be important to follow up. The control DNA image was obtained by adding polymer of $1: 0.5$ (DNA : polymer) weight ratio where polymer was used for enhanced DNA binding instead of divalent metal cations. A4B4 2.0 was complexed with DNA at a weight ratio of $1: 30$ (DNA : polymer). The particles were spherically shaped without uncomplexed DNA at $0 \mathrm{~h}$. After $24 \mathrm{~h}$. the polyplex held its globular shape but swelling was observed at the surface of the polyplex by polymer degradation. Also. after $48 \mathrm{~h}$ of incubation. polyplexes showed similar images but the slow degradation kept the polyplexes in almost the same sizes as $24 \mathrm{~h}$ and still no protruding DNA 


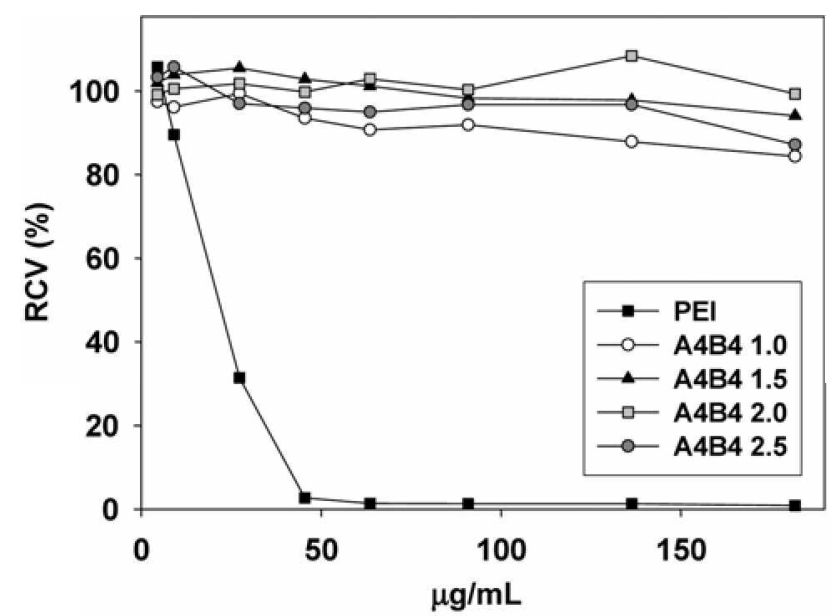

Figure 4. Cytotoxicity assay in HepG2 cells by MTT method. The increasing amounts of polvmer were treated to cells for $48 \mathrm{~h}$.

was observed.

Cytotoxicity was conducted by MTT assay method. where PEI was used as control (Figure 4). Cells were grown for 24 $\mathrm{h}$ and indicated concentrations of polymer were added and left for $48 \mathrm{~h}$ exposure. All A4B4 polymers showed over $85 \%$ cell viability especially A4B4 1.5 and A4B4 2.0 showed almost no toxicity even at a very high concentration as 200 $\mu \mathrm{g} / \mathrm{mL}$.

Transfection efficiencies of all A4B4 polymers were investigated using luciferase reporter gene assay by luciferase activity with total proteins. in the presence or absence of senum. using PEI $(1: 1=$ polymer/DNA) as a control (Figure 5). HepG2 were grown in MEM containing $10 \%$ FBS in a $5 \% \mathrm{CO}$ incubator at $37^{\circ} \mathrm{C}$ and seeded in a 24 -well plate at a density of $5 \times 10^{4}$ cells/well. The polyplexes were added to a $10 \%$ FBS containing condition and incubated for $48 \mathrm{~h}$ for $(+)$ serum condition. The polyplexes were treated to cells without senum for 4 h. then washed and replaced with fresh. $10 \%$ FBS containing medium for further $44 \mathrm{~h}$ for $(-)$ serum condition. Then all media was removed, washed with PBS. and followed by lysis. Increasing polymer weight ratios up to 30 showed increasing transfection efficiency. where a plateau was reached. A4B4 1.5 had good transfection efficiencies at low ratios. resulting from higher $\mathrm{M}_{w}$ and size regularity compared to other polymers. The usual protocol for transfection excludes FBS for easier cell uptake and also to avoid polymer aggregate formations. but $\mathrm{A} 4 \mathrm{~B} 4$ polymers showed good transfection efficiencies in the presence of FBS. especially better transfection effects were observed at low weight ratios as 10 and $20 \mathrm{by}$ A4B 42.5 .

The polyplexes had regular. globular shapes whereas polymer itself had a random structure. To follow the degradation profiles in detail. two groups of samples were studied for the extended time. One group was the polymer group and the other group was polyplex (polymer/DNA. weight ratio of 30) group. They were both incubated under same conditions and taken at indicated time intervals. measured with PicoGreen reagent (Figure 6). As the B4 ratio increased from 1.0 to 2.5 , the increased amine concentration provided by $\mathrm{B} 4$
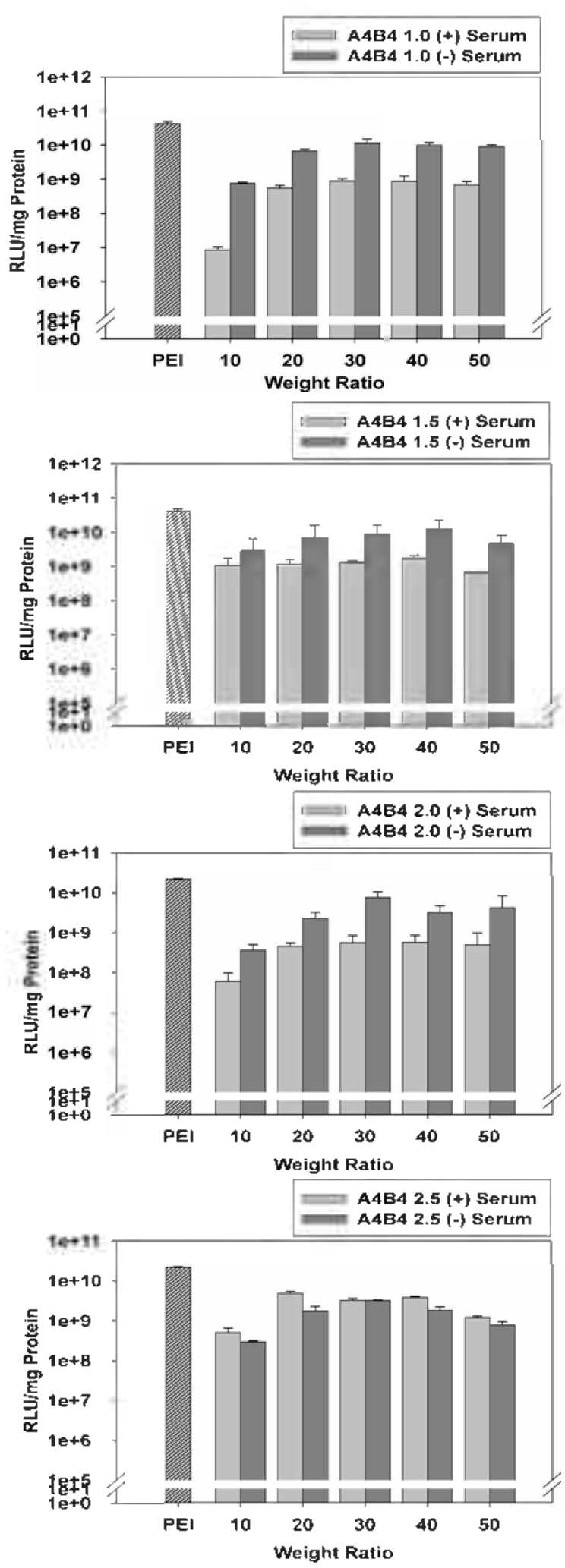

Figure 5. Transfection efficiencies of A4B4 polymers at increasing weight ratios (polymer/DNA) in HepG2 cells.

monomer will result in the formation of more anide bonds in the polymer backbone. Increased amide bonds in the polymer core structure will slow down the degradation rate than other polymers constructed at lower amine concentrations. 

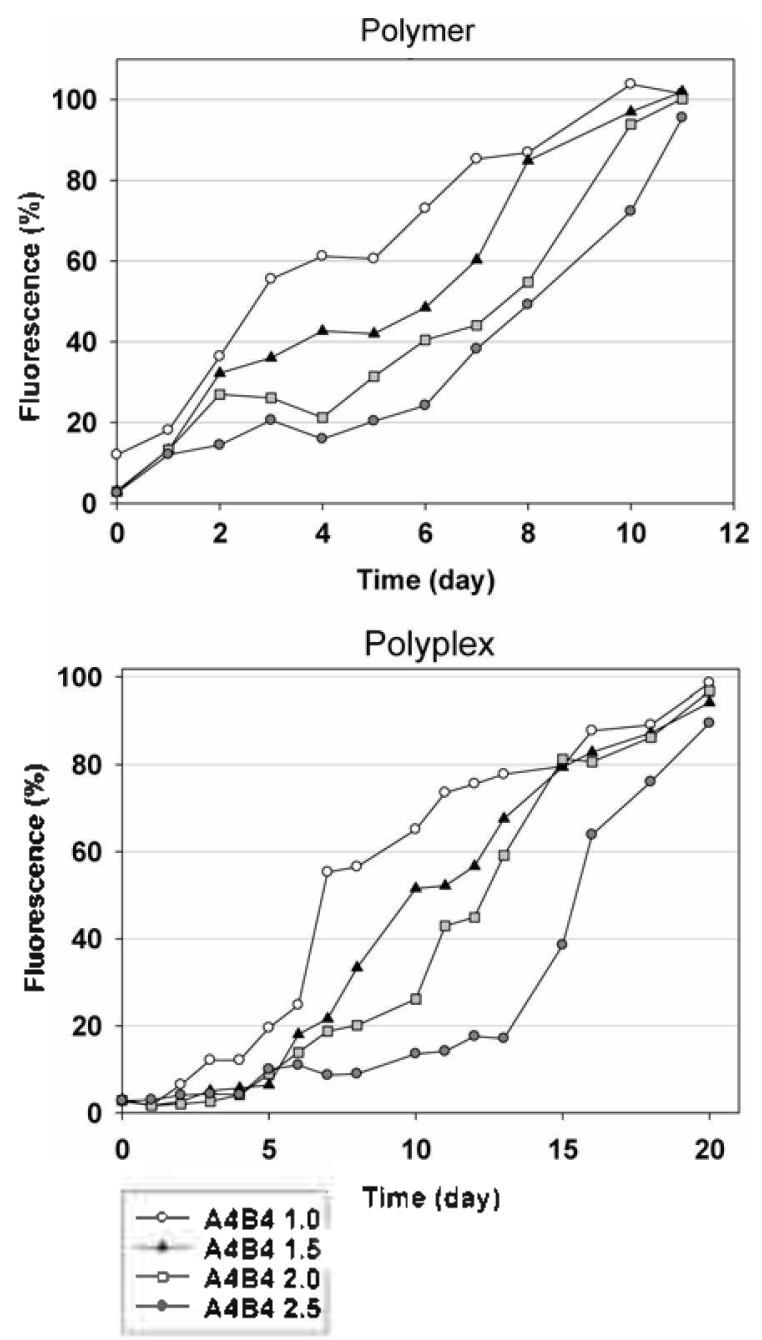

Figure 6. Degradation assay in terms of time (day) in PBS buffer conditions using PicoGreen reagent.

since labile ester bonds degraded fast under aqueous conditions especially in the presence of primary amines. In average. the free polymer showed faster degradations with simple and gradually increasing patterns. while all the polyplexed forms stably protected DNA for several days under $20 \%$ fluorescence before fast release was observed. Among the four polymers. as expected. A4B+1.0 had the fastest degradation tendency and the slowest degradation rate was obtained by A4B42.5. A4B4 1.0 polymer completely lost its DNA condensing capability after 10 day's but the fluorescence was still under $70 \%$ at day 10 when it was kept in the polyplexed form. A4B 42.5 could retain DNA safely for more than 12 day's under $20 \%$ fluorescence in the polyplexed form. even about 5 days in its free polymer form. Different B4 monomer ratio resulted in different bond compositions of polymer structure which resulted in different degradation rates. which could be manipulated to control the release time of complexed DNA using the mixture of different polyplex solutions of A4B4 polymers. For example, mixing A4B4 1.0 and $\mathrm{A} 4 \mathrm{~B} 42.5$ polyplexes. two step release of DNA will be obtained. as fast initial burst for 5 days and slow enduring release for over 20 days.

In summary: four degradable A4B4 polymers were synthesized by double-monomer method with excellent solubility: After the modification of the surface functional groups with primary amines. the polymers self-assembled with plasmid DNA in a spherical shape showing good transfection efficiencies even in the presence of serum. The polymers had different degradation tendencies. since the degradation was regulated by monomer B4 concentration at the syinthesis step. Their low to no toxicity and slow degradation rates would contribute to the long-term in vivo gene delivery. and even therapeutic treatment applications.

Acknowledgement. This work was supported by the Korea Health 2l R\&D Project of The Ministry of Health \& Welfare. Republic of Korea (A04-0004). and the Gene Therapy Project of The Ministry of Science and Technology (M1053403004-05N3403-00410).

\section{References}

1. Kabanov. A. V: Felgner. P. L:: Seymour. L. W. Self.Assembling Conplexes for Gene Delnen; From Laboratony to Chinical Trial. John Wiley and Sons. Inc.: New York, 1998.

2. MeTaggart, S: Al-Rubeai, M. Biotechol. $A d$ : 2002. 20, 1-31

3. Katri, T': Morgan, D:; Krahl, T': Sarvetnick. N.: Sherman. L.; Verma. I. Proc. Natl Acad Sci. US.A. 1998. 95, $11377-11382$.

4. Lyt11. D. M.: Langer. R. J. Ant. Chent. Soc. 2000. 122. 1076l10786.

5. Lim. Y.: Kiml. C.: Kim. K.: Kim. S. W: Park. T. J. Am. Chem. Soc. 2000. $122,6524-6525$.

6. Lynn. D. M; Langer, R. J. Am. Chem. Soc. 2000. 122, $101761-$ 10786 .

7. Wang. J.: Mao. H.: Leong. K. W. J. An. Chem. Soc. 2001 . 123. 9480)-9481.

8. Lim. Y.: Kim. S.: Lee. Y: Lee. W.: Yang. T.: Le. M.: Suh. H.: Park. J. J. Am. Chem. Soc. 2001, 123. $24601-2461$.

9. Lim. Y; Kim, S.: Suh. H.: Park, J. Bioconingate Chem. 2002. 13. $952-957$.

10. Kim. H. T.: Kwon. M. S.: Choi. J. S.: Yang. S. M.: Yoon1. T. K.: Kiml. K.: Park. J. Biontaterials 2006. 27. 2292-301.

11. Gao. C.: Yan. D. Prog. Polm. Sci. 2004. 29. 183-275.

12. Choi. J. S.; Nam. K.: Park. J; Kim. J.; Lee. J; Park. J. d. Controlled Release 2004, 99. 445-456. 